University of Wollongong

Research Online

Faculty of Law, Humanities and the Arts Papers (Archive)

Faculty of Arts, Social Sciences \& Humanities

2007

Law's empiricism of the object: how law recreates cultural objects in its own image

Marett Leiboff

University of Wollongong, marett@uow.edu.au

Follow this and additional works at: https://ro.uow.edu.au/lhapapers

Part of the Arts and Humanities Commons, and the Law Commons

Research Online is the open access institutional repository for the University of Wollongong. For further information contact the UOW Library: research-pubs@uow.edu.au 


\title{
Law's empiricism of the object: how law recreates cultural objects in its own image
}

\begin{abstract}
Watch an antique or collectables show on television, and more often than not, one segment is devoted to testing the knowledge of an expert panel (and sometimes members of the public) with a problem or 'mystery' object. The object of the exercise (no other word will do so the pun must stay), is to find out what the object actually is, what it was used for, and when it was used. Sometimes the experts know what it is, but more often than not, the host has to tell them. The only way an object can provide some kind of objective knowledge about itself is in terms of a weighing and measuring exercise, but without more, the object is bare, meaningless, and lifeless. The appearances of objects can be deceiving, as Mieke Bal is telling us, because pure and certain objects are meaningless without context, meaning, value, or significance. Meanings and values discursive factors - have to be imposed on these objects in order to make sense of them as objects of culture or objects of value. The only things that an object can tell us with precision are those things we impose upon it.
\end{abstract}

\section{Keywords}

recreates, law, cultural, objects, own, object, empiricism, its, image

\section{Disciplines}

Arts and Humanities | Law

\section{Publication Details}

M. Leiboff, 'Law's empiricism of the object: how law recreates cultural objects in its own image' (2007) 27 The Australian Feminist Law Journal 23-50. 


\title{
LAW'S EMPIRICISM OF THE OBJECT: HOW LAW RECREATES CULTURAL OBJECTS IN ITS OWN IMAGE
}

\author{
Marett Leiboff*
}

\subsection{INTRODUCTION: FINDING LEgAL CERTAINTY?}

Things, called objects for a good reason, appear to be the most 'pure' form of objectivity."1

Watch an antique or collectables show on television, and more often than not, one segment is devoted to testing the knowledge of an expert panel (and sometimes members of the public) with a problem or 'mystery' object. The object of the exercise (no other word will do so the pun must stay), is to find out what the object actually is, what it was used for, and when it was used. Sometimes the experts know what it is, but more often than not, the host has to tell them. The only way an object can provide some kind of objective knowledge about itself is in terms of a weighing and measuring exercise, but without more, the object is bare, meaningless, and lifeless. The appearances of objects can be deceiving, as Mieke Bal is telling us, because pure and certain objects are meaningless without context, meaning, value, or significance. Meanings and values discursive factors - have to be imposed on these objects in order to make sense of them as objects of culture or objects of value. ${ }^{2}$ The only things that an object can tell us with precision are those things we impose upon it.

The object, despite these deficiencies, is prized by the legal enterprise (a term I will use to encompass law as doctrine, law within its categories of meaning, and law in the hands of its practitioners) because it provides a sense of clarity and certainty that brooks no opposition. If something can be described, quantified, weighed and measured, then that thing and its existence is incontrovertible, by apparently providing knowledge about the object in its clearest and most precise mode. It assumes the veracity of the object as a physical presence as a fact, which can

* Marett Leiboff is a Senior Lecturer in the Faculty of Law at QUT in Brisbane, Australia. She undertakes research into law and the arts and creativity, media law, and legal theory, focussing on the way that the courts make decisions about art, culture and creative content in a broad range of legal categories. M.leiboff@qut.ed.au My thanks to the anonymous referees and editorial boatd for their very helpful comments.

1 Bal Mieke 'Telling Objects: A Narrative Perspective on Collecting' in Elsner John and Roger Cardinal (eds) The Cultures of Collecting Melbourne University Press Melbourne 1994 p 99.

2 Leiboff Marett 'clashing things' in William MacNeil and Peter Hutchings (eds) (2001) 10(2) Law's Cultural Mediations: Special Issue Griffith Lan Review 294 
provide a trustworthy source of information about the object itself. But as the example of the television collectables program shows, objects can only do so much, and explanations about the object must be imposed externally on the object. While these may be described as facts about the object (who owned it, who painted it and so on) the legal enterprise characterises these interventions, generally speaking, as opinion. Opinions, by their nature, are uncertain, and always suspect because they are based on the views of the people who make them. They cannot, unlike objects, be certain at all. Yet as the example of the 'mystery object' shows, objects as they are used in the social world are fallible because they have no meaning other than that placed upon them, such as their associations with a particular historical person, or because of their rarity.

However, this reliance on the veracity of objects is fundamental to a range of areas of law from the law of contract to personal property law, and informs the rules of evidence through decisions whether or not to admit expert 'opinion'. As will be seen shortly, the idea that the fact of an object can be determined with precision, but that opinions are suspect, is imbued within the stuff of the legal enterprise. Yet law's practitioners are mostly unaware that the fact/opinion divide was a creation of seventeenth and eighteenth century philosophical empiricism which suited the emerging commercial temperament of the legal doctrines and categories that took their modern shape during the same period. The fact/opinion divide embedded itself within law because it has the appearance of making legal decision-making more certain, more rational, and more objective. However, I will argue here that not only does it make some types of decisionmaking less certain, other methods based around the discursive practices used to create meanings about objects (which the legal enterprise would classify as opinion) have the potential to create a more solid and certain set of meanings about objects.

I will suggest that the duality of fact and opinion is a divisive analytical tool that can alter the appearance of meanings and value of an object, and rather than ensure a certainty of outcome in cases involving art and cultural objects, may result in greater uncertainty than if the legal enterprise used a less divisive method to make decisions about the veracity of objects. Indeed, a 'whole of object' method, which is used by museums practitioners to make decisions about the cultural value and cultural significance of objects (such as knowing what a 'mystery object' is, what makes it valuable or interesting) allows for a very different conception of what 'makes' an object. Rather than operating as a dualism between the objective properties of an object and the subjective opinions about the object, the object functions discursively. It is made up of its meanings, which may be many and varied, of which its physical form is only one of a range of factors that makes the object 'what it is'.

In this article, I will suggest that the legal enterprise is blind to the effect its rationalist and empiricist methodologies have on its decision-making about art or cultural forms, or cultural or artistic value or merit (to be called here a 'cultural object'). As will be seen shortly, I suggest it uses a robust 'commonsense' that is ostensibly certain, objective and factual, on which it bases its decisions. ${ }^{3}$ It avoids making decisions based on what it calls opinion or those things on which the value of a cultural object is based - its authenticity, its beauty, its historical value and the like. 'Opinion', so-called, is simply a question of appearance, able to be rendered unstable through the

Kirby Michael The Hon Justice 'Hanging Judges and the Archibald Prize' (2006) 11 Media and Arts Law Review 300. 
tricks of smoke and mirrors, which cannot be measured accurately because they are lacking the hallmark of precision - a physical, verifiable thing. ${ }^{4}$ Yet 'opinion' encompasses everything on which artistic, cultural and creative value is based - except the physical object to which it refers.

Decision-making is so much more certain, cleaner if you like, when aesthetics or value judgments are put to one side, and law directs its gaze to factors on which it can make valid decisions based on determinable, verifiable and certain fact. ${ }^{5}$ For the legal enterprise, this means a physical object or some other kind of physical feature of an object, but one which is stripped of other meanings or signifiers or value. The common law tradition uses methods which are inescapably, intractably those of the empiricism of the British enlightenment, methods which trust what can be seen or proved, and which distrust the validity and veracity of anything else. ${ }^{6}$

Here, I will suggest that law's reliance on the physical and verifiable may result in a (textual) reconceptualisation and reconstruction of a cultural object into meaningless physical components - a Victoria Cross medal as a piece of metal, a rare aeroplane as a piece of scrap, a picture by Constable as an image of a cathedral. While this approach seeks to render decisionmaking objective and rational, a very different result can be reached: that the object as a text can be recreated or remade. ${ }^{7}$ The legal enterprise assumes that the dualism it imposes ensures the most certain and effective decision-making in these cases. Yet, extraordinary and partial readings of the text of the object can result because the object can be physically cast in a range of forms, and may be 'read' differently in its different physical manifestations. At an extreme level, it can be transformed into a nonsense. For instance, in 1981, in order to avoid customs regulations, a rare Spitfire MK 8 MV 154 was recast (so to speak) by its exporter on the relevant document into its most fundamental physical form: 'aluminium junk'. ${ }^{8}$ In a sense, the truth of the object was told because it was constructed of the material so described and as an old aircraft could be conceived of as 'junk'. In effect, the fact/opinion divide can actually encourage this kind of rereading or reconstruction of the object.

Indeed, the plane's value lay in factors that the fact/opinion methodology (which I will term 'law's empiricism of the object') cannot accommodate. To call its history and the events associated with it 'opinion' is as nonsensical as calling the aircraft junk. But that is what the fact/opinion divide imposes - the fact of the physical materials of the aircraft on the one hand, and other factors such as its wartime record based in opinion on the other. The common law methodology has no language to understand the value of an object in discursive terms, based on values that made this aeroplane significant, such as its social and historical value. Yet the concept of the discursive object is found in Australia's Protection of Movable Cultural Heritage Act 1986 (Cth) ('the legislation' or the 'PMCH Act'), which seeks to protect culturally significant objects for the

\footnotetext{
Karlen Peter 'Fakes, Forgeries, and Expert Opinions' (1986)16 Journal of Arts Management \& Law' 5.

Palmer Norman 'Misattribution and the Meaning of Forgery: The De Balkany Litigation' (1996) 1 Ant Antiquity and Law 49 Jendurine $v$ Slade (1797) $170 \mathrm{ER} 459$.

Leaf v International Galleries [1950] 2 KB 86; Tbomson v Cbristie Manson \& Woods Limited [2005] EWCA Civ 55

Simpson's Solicitors Intemational Protection of Cultural Material undated <http://www.simpsons.com.au/documents/visarts/ visarts89/22IntnlP.pdf>.
} 
nation by refusing their export from Australia. ${ }^{9}$ Decision-making is meant to be based around a web of provisions found within the legislation proper and its associated regulations designed to test the value of the object within discursive terms (the 'cultural significance provisions'). ${ }^{10}$ Operating at the intersection of law, art, culture, heritage and nation, the legislation assumes that decision-making is to be based around the discursive object, but as I will show later in this article, the legal enterprise interposed the fact/opinion divide into a decision-making process established by the legislation.

Indeed, such an approach can be harmful to effective and reasoned decision-making about cultural objects, but the fact/opinion methodology is so deeply imbricated into legal consciousness and practice that the legal enterprise cannot imagine objects any other way. In the leading case of $R e$ Truswell, ${ }^{11}$ the Administrative Appeals Tribunal ('the AAT') struggled to explain how a physically insignificant object with immense cultural significance could be protected under the legislation, ${ }^{12}$ because it could not conceive of an object other than through the lens of fact and opinion. In deciding that it could be protected, ${ }^{13}$ the AAT used a piece of sophistry to reinscribe the fact/opinion divide into the legislation. It did so by creating a new version of the fact/opinion divide by distinguishing between a tangible (by which it meant the fact or physical properties of the object) and an intangible (the factors which would otherwise be classed as opinion) so that it could find a way of protecting the object, a Victoria Cross medal.

But the effect of the AAT's decision was to render the VC empty and barren. Its methodology was profoundly empiricist, because it was only able to accept the existence of the object in its physical manifestations, to be treated no differently from the aluminium junk that was the Spitfire. ${ }^{14}$ It had no language to appreciate or comprehend the object in all its discursive whole, even though the cultural significance provisions of the PMCH Act assumed that decisionmaking about objects would take a whole of object, discursive approach. However, while a 'good' result was achieved - the VC was refused an export permit and had to stay in Australia - the intention behind the legislation was corrupted by the interpolation of a version of the fact/opinion divide - now expressed as a tangible/intangible divide. At the heart of my argument lies a concern that even when legislation (like this) did not require, want, or even need a distinction between fact and opinion, physical and non-physical, tangible and intangible to be

9 It has also been assumed that cultural heritage is 'manifested in physical objects - things which can be seen, touched, used, even revered - such as buildings, monuments, tools, weapons, machinery, art works, clothing, religious objects' Ley John F Australia's Protection of Movable Cultural Heritage: Report on the Ministerial Review of the Protection of Movable Cultural Heritage Act 1986 and Regulations Australian Government Publishing Service Canberra $1991 \mathrm{p} 11$.

10 Sections 7, 8 and 10 of the Protection of Movable Cultural Heritage Act and the National Cultural Heritage Control List (the List'), which is located in Schedule 1 of the Protection of Movable Cultural Heritage Regulations 1987 (Cth), make up the 'cultural significance provisions'.

11 Re Truswell and Minister for Communications and the Arts (1996) 42 ALD 275. This case will be referred to a shortened version of $\mathrm{Re}$ Trussell within the text.

12 Re Truswell and Minister for Communications and the Atts (1996) 42 ALD 275, 291 [97].

13 Re Truswell and Minister for Communications and the Arts (1996) 42 ALD 275

14 Re Truswell and Minister for Communications and the Arts (1996) 42 ALD 275, 295 [125]. 
drawn, the AAT imposed it anyway. ${ }^{15}$ The conception of objects as understood by the legal enterprise was interposed into a legislative regime based in and around the idea of the discursive object - the object whose existence matters because of the meanings ascribed to it.

In many respects, this article is using the decision in $R e$ Truswell as a litmus, or as a canary down the mine shaft, to test a wider set of concerns about the use and usefulness of the fact/opinion as it is used by the legal enterprise across all categories of law affecting visual arts, creativity and culture. In this respect, I draw on Rosemary Coombe's concern by engaging with the assumptions contained within existing legal categories. She argues that:

there is little to warrant the construction of an ideal bridge to join two autonomous realms designated as "law" and "culture" insofar as this would reinforce the metaphysics of modernity that enabled their emergence as discrete and naturalized domains of social life. An exploration of the nexus of law and culture will not be fruitful unless it can transcend and transform its initial categories. ${ }^{16}$

So I do not mean the analysis I offer here to be limited to the ambit of the PMCH Act only, which is, in any event a small and relatively insignificant target, and instead serves as an exemplar for the limitations of the practices and methods of the empiricism of the object when applied to the law affecting cultural objects, whether it be contract law, personal property law, cultural property law, or the rules of evidence. I will suggest that by using the fact/opinion divide, the legal enterprise is harmful to the environment in which cultural objects and other products of creative activity circulate. In part, one of the reasons why this is the case is because the legal enterprise holds onto seventeenth and eighteenth century methods of empiricism under which it makes its decisions about the veracity of cultural objects.

\subsection{Empiricism, Culture, ObJects AND the LAW}

The extent to which law is imbued with the language and method of the Enlightenment is, if we were to ever give it much thought, not a bad thing from the standpoint of doctrinal readings of the law. Enlightenment methods, especially as they find their way into case law have become valorised as rationality in action, and allows the legal enterprise to avoid making value judgments about matters on which it can claim no ability, such as deciding whether art is any good or not, or if a work of art was painted by the person to whom a work was attributed.

15 Cf Black CJ and Gummow J in W'aterhouse v Minister for the Arts and Territories, (1993) 119 ALR 89, 95: 'the Act operates upon established common law concepts of ownership and possession of chattels'.

It should be noted that this observation was not made in the context of decision-making under the cultural significance provisions, but the broader role and function of the legislation.

16 Coombe Rosemary J with Jonathan Cohen 'The Law and Late Modem Culture: Reflections on Between Facts and Norms from the Perspective of Critical Cultural Legal Studies' (1999) 76 Denver University Law Reriew 1029 p 1031; Coombe Rosemary J 'Contingent Articulation: A Critical Cultural Studies' in Sarat Austin and Thomas R Kearns (eds) Law in the Domains of Culture University of Michigan Press Ann Arbor 1998 p 21-22. 
But as Roy Porter's account of the British Enlightenment shows, this rationality sought to tame the untameable, and to embed a particular idea about certainty that could lead to an inflexibility verging on the ludicrous:

Setting reality above verbality, the coming English empiricism ... looked favourably on quantification. Were not numbers, at least, unambiguous and trustworthy? Instead of using only comparative and superlative Words and intellectual Arguments', explained Sir William Petty, a founder fellow of the Royal Society, 'T have taken the course ... to express myself in Terms of Number, Weight, or Measure.'"

But this idea that the world could and should be locked into an unchanging and unchangeable reality based in the physical is fundamentally law's method - to focus on the provable, verifiable and factual. It is empiricism in action. While rendered in a more sophisticated language, for the purposes of its analysis, the legal enterprise has tended to adopt the scientific and empiricist mode of Enlightenment thought that privileges the physical, and therefore determinable, materiality or manifestations of objects. The empiricism so created founded knowledge in facts and facts alone, and entered into the law through the intellectual climate of the period. As my earlier description of the empiricism of the object has suggested, the legal enterprise has created doctrines, categories and methods based on and drawn from a Baconian and Lockean insistence that true knowledge can only be based on that which is fundamentally observable: ${ }^{18}$ the very stuff of facts. Nothing else can be trusted to produce untainted facts. Indeed, Porter observes that 'Locke shared Bacon's impatience with scholastic syllogisms ... empirical knowledge, by contrast, traded in honest matters of fact'. ${ }^{19}$ Objects, as a physical mass, can be described, categorised, weighed and measured by external observers, ${ }^{20}$ and may be safely relied upon as a site of analysis because of their stable and objective form, and because they can be observed by the senses. ${ }^{21}$

This analytical approach privileges stable and determinable physical properties, which can be cast as 'fact', over questions of taste, quality, authenticity, and attribution, which are cast into the subjective and changeable realm of 'opinion'.22 While empiricism as a method developed gradually over two centuries, by the end of the eighteenth century, its practices and assumptions

17 Porter Roy Enlightenment: Britain and the Creation of the Modern World Penguin London $2000 \mathrm{p} 54$.

18 Porter notes that in the Advancement of Learning (1605), Bacon observed that science had to start with the senses, as it was a basis for grounding inquiry in observation and experiment. Porter, above $\mathrm{n}$ 17, 56-57. Cf Porter's observation of Descartes: 'Though the senses were irreparably deceptive, reason was capable of establishing truth'. Porter, above $\mathrm{n} 17$, 55.

19 Porter, above n 17,63 .

20 Munzer Stephen R A Theory of Property Cambridge University Press Cambridge $1990 \mathrm{p} 71-74$. Munzer argues for an 'essential materiality of property', which means that 'material things must be involved, at some point, even in the case of intangible property',

21 For a critique of ocularcentrism, or the privileging of the sense of sight by law: Bently Lionel, 'Introduction' in Bently Lionel and Leo Flynn (eds) Law and the Senses: Sensational Jurisprudence Pluto Press London 1996.

In relation to early intellectual property law, the idea of a property which could be stolen through a pane of glass and carried off by the eye without being found on a person offended the empiricist sensibilities of the law'. Sherman Brad and Lionel Bently The Making of Moderm Intellectual Property Law: the British Experience, 1760-1911, Cambridge University Press, Cambridge, 1999, 20.

22 Palmer, above n 5, 49. 
had become embedded into the legal consciousness, classically expressed in Lord Kenyon's judgment in Jendwine $v$ Slade, itself the origins of the application of the fact/opinion divide insofar as it applies to cultural objects, that two pictures supposedly by Lorrain and Teniers:23

were the work of artists some centuries back, and there being no way of tracing the picture itself, it could only be a matter of opinion whether the picture in question was the work of the artist whose name it bore, or not. ${ }^{24}$ (emphasis added)

Within the empiricist temperament of the late eighteenth century, no wonder Lord Kenyon was so impatient with the disputed claims for the Lorrain and the Teniers in Jendwine $v$ Slade, ${ }^{25}$ for these claims could not be proved by looking at the paintings. The paintings were nothing more than an amalgam of their physical properties, or the visible subject matter or image in front of the viewer. Within law's analysis, these were facts. Who the artists were, was nothing other than 'comparative and superlative Words and intellectual Arguments', or opinion, and therefore incapable of proof. If you were not there, and could not see for it for yourself, a painting could never be proved for a fact. It was all mere opinion - Sir William Petty's 'comparative and superlative Words and intellectual Arguments'. Law followed: it too could only trade in facts. The embedding of the fact/opinion divide within the mindset of the legal enterprise was assured.

But the history surrounding this case provides a very different reading of these events: impatience and irritation with the competing claims of experts appears to be the key reason for the decision. So though on its face the case established the 'fact/opinion' divide that prevails in the legal enterprise, a different reading of the case can be found in the popular reporting of its comings and goings, which showed that Jendwine $v$ Slade, ${ }^{26}$ was the subject of enormous contemporary interest. David Phillips' account of what happened from popular reports of the case, suggests that it was judicial impatience with a long line of connoisseurs called as witnesses, whose evidence 'seems to have consisted of nothing but connoisseurial assertion', ${ }^{27}$ that contributed to Lord Kenyon's intense irritation with the opinions expressed in the case. In other words, they did not or could not account for reasons why they agreed or disagreed with their views as to the authenticity of the paintings. Thus, the fact of the object was not examined or considered in the way asserted by the decision, yet the case stands for the proposition that law will not involve itself in matters of taste or connoisseurship, which it treats as 'opinion', in the absence of express contractual conditions or warranties. ${ }^{28}$ It hardened the sense that 'enlightened

23 (1797) 170 ER 459. Cf Power v Barbam (1836) 4 A.\& E. 473, where Jendwine $v$ Slade was able to be distinguished on the ground that the painter, Canaletto, who had only died in 1768 , was 'not a very old painter'.

(1797) 170 ER 459.

(1797) 170 ER 459

(1797) 170 ER 459.

Phillips David Exbibiting Authenticity Manchester University Press Manchester 1997 p 73-74.

28 Lord Atkin, in Bell $\nu$ Lever Bros. [1932] A C 161, 224, in dicta, observed: 'A buys a picture from B; both A and B believe it to be the work of an old master and a high price is paid. It turns out to be a modern copy. A has no remedy in the absence of representation or warranty'. See also representations made in respect of the operation of $\mathrm{s} 52$ of the Trade Practices Aat 1975 (Cth) in the decision in The Saints Gallery Pty Ltd v Plummer (1988) 80 ALR 529. 
thinkers set res over verba', ${ }^{29}$ 'thing over words', 'fact' over 'opinion'. The decision has influenced attitudes to the veracity of objects in all areas of law since.

In doing so, the legal enterprise imposed one of the most stringent readings of caveat emptor on buyers of art, which effectively protects those trading in art - auction houses, dealers and the like - from liability in contract, tort, and sales of goods. While it has been suggested that the law simply adopts the practice of the art 'trade', law has allowed the trade to develop its practice in this way: 30

English courts rarely attach contractual force to statements about the authorship of works of art. For the most part they seem, in common with the trade, to prefer to treat such statements as expression of opinion rather than of fact. ${ }^{31}$

This ultimately becomes a question of the chicken and the egg, for the law has set the standard of conduct, from which the 'trade' benefits. It suggests that the trade functions as a mere conduit for the sale of art and cultural objects, and it also assumes the legal enterprise plays no part in creating the circumstances in which that trade functions. The reality is that both are actively involved in the creation of the cultural value of the object; as Bourdieu's work shows the 'trade's' view of itself is a fiction designed to protect the 'trade' from liability, and shows that human agency is fundamental to the creation of value in the markets in the cultural field. ${ }^{32}$ Cultural institutions and industries are actively involved in the creation of cultural value and cultural significance. This includes art market actors, such as dealers and auction houses, and specialist institutions, such as museums and galleries. So events normally excluded from contract formation, such as media interviews, books, inclusion of objects in exhibitions, or decisions to prevent an object from being exported because of its cultural significance, and so on, are part of the process of value creation and value construction. Instead of simply dealing with things, or words or names, there is a very real sense in which these actors create cultural value or significance. As a result a very different reading of the concept of fact and opinion results, which does not see opinion as divorced from the object. Instead, the actors create value. Law's method of fact/opinion res/verba cannot be seen as anything other than a fiction, which ultimately protects actors in the market in arts and cultural objects from liability for their 'opinions' about physical objects.

29 Porter, above n $17,5$.

30 Crewsdon Richard 'Some aspects of the law as it affects dealers in England' in Lalive Pierre (ed), Intemational Sales of Works of Art (Geneva Workshop, 11-13 April 1985) International Chamber of Commerce No. 436 Paris c.1988 p47.

31 Palmer, above n 5, 49.

32 Bourdieu Pierre (trans. Susan Emanuel) The Rules of Art: Genesis and Structure of the Literary Field, Polity Press Cambridge 1996 p 170. 


\subsection{RECONCEIVING THE EMPIRICISM OF THE OBJECT: THe Discursive OBJeCT}

The idea that objects may express or contain an inherent certainty of meaning was not confined to the legal enterprise. Empiricism and its methods were also deeply imbricated into the practices of any number of other fields of practice, including those involved in keeping, managing and interpreting collections held in museums and galleries.But these other fields of practice have now shifted to understand objects within their discursive and narrative conceptions. ${ }^{33}$ They too had relied on the methods of res and verba until the 1960s, in that it was possible to rely on the physical presence of objects as the truth-teller of its value and meaning. ${ }^{34}$ They now assume that the physical form of the object is only one of a range of factors that constitute its values and meaning, but is valueless without more. ${ }^{35}$ 'Physical objects are meaningless without social content. Idea and expression are not separable parts, but the same social construct'. ${ }^{36}$

Unlike the methods held onto by the legal enterprise, an object's physical properties are treated as one facet relevant to the process of understanding its cultural value and cultural significance. Instead, there is an acceptance that meanings about objects are socially constructed by a relevant community in a contingent time and space. In other words, meanings about objects are not locked down at a particular point in time, not because the physical properties of the object changes, but because the meanings about the object change. ${ }^{37}$ A 'mystery object' would have been commonplace once, its meaning assured. A number of years later, its physical properties intact, could become meaningless.

These methods accept that meanings are something that are ascribed, rather than assuming that objects are capable of being described. They accept and acknowledge that some actor has to make a decision about what makes the object meaningful and valuable. Curiously, despite its claims to avoid these questions, Douzinas, Warrington and McVeigh have shown how the legal enterprise does create meanings despite assertions that it does not. In assessing a decision as to whether a Henry Moore sculpture could be placed in a Sir Christopher Wren church, they have argued that law does engage in this ascriptive process by filling in the spaces between the visible and invisible, so that by:

33 Vergo Peter (ed) The New Museology Reaktion Books London 1989.

34 Taborsky Edwina 'The Discursive Object' in Pearce Susan M (ed) Objects of Knowledge The Athlone Press London $1990 \mathrm{p} 60$.

35 Among the key literature in this field that have influenced the approaches towards the construction of a discursive cultural significance is: Pearce Susan M (ed) Museum Studies in Material Culture Leicester University Press Leicester 1989; Pearce (1990), above n 34; Hooper-Greenhill Eilean Musetws and the Shaping of Knowledge Routledge London 1992; Pearce Susan Museums Objects and Collections: A Cultural Study, Leicester University Press Leicester 1992; Elsner John and Roger Cardinal above n 1; Pearce Susan M (ed) Interpreting Objects and Collections Routledge London 1994.

36 Pearce (1992) above n 35, 21.

37 For issues relating to the ability to value public collections, see especially Carman John Garry D. Carnegie and Peter W. Wolnizer 'Is archaeological valuation an accounting matter?' (1999) 73 Antiquity $143 \mathrm{p} 147$. They argue that archaeological value and financial value cannot be compared or ranked, and suggest that there is a need to justify practices rather than material. 
pronouncing on the content and specificity of other discourses, law actually enters the dangerous, fluid non-space between self and other, imbrication and distance, inside and outside. A third term emerges, a space in between which defies and defiles the decency of these distinct entities and proprieties. ${ }^{38}$

Exactly the same methods are used when the law has to stitch together meanings about objects, but objects can be misread within this ascriptive process because of the emphasis on the truthfulness of the physical. The cultural significance provisions of the PMCH Act, similarly, leave interstices which must be filled to create meanings for objects: whether or not they are a particular type of object that is of such importance to Australia that it should never leave the country. But rather than considering all the elements that make up an object's value, which the PMCH Act assumes, the methods used by the AAT say that the only way of reading the objects is to impose res and verba, dividing the physical from the narrative.

The legal enterprise is easily able to make these judgments when facts of objects fall into pre-ordained categories - a diamond of a certain size, colour and quality does not present any hurdles to ascertain what it is. A piece of glass masquerading as a diamond can be easily discovered by visual examination, but the problem would be if the diamond were also said to be of value because of a person with whom it were associated - a 'fact' only capable of being determined by an opinion on which it is based. Its value or significance would be rendered lesser if it had not been used by that person, but the diamond cannot provide this information (unless some DNA had attached to it). Its meaning and value can only be based on an understanding in a given time and through the abilities of a mediating actor who will make an assessment or determination of its association. While another may disagree with that assessment, a judgment call must be made one way or another at a particular point in time, though it may be later reassessed or reascribed. The value made here is not based in and around a differentiation of opinion based on the physical properties of the diamond but the circumstances surrounding the diamond. It will still be a diamond and not a piece of glass and it will have a value attached to it in terms of its physical properties. It will not be a different physical object because its meanings have changed, but its now debased meaning will negate any discursive significance. As a discursive object, it will have changed dramatically, but the fact of its physical presence is not altered at all. Law cannot explain this distinction within its current mode of analysis which assumes the physical object will be able to tell all the truths of the object.

A different reading applies to objects that are pbysically insignificant, or inherently physically valueless, like a piece of glass masquerading as a diamond. The glass has no value when it is assessed through the process of weighing, measuring and describing, and the legal enterprise, only looking at what it is not, has no language to explain why it may have a discursive significance. This significance may be derived from some kind of social situation which makes it fundamentally important, such as its associations with a particular famous person who wore it pretending that it were a diamond. Again, there is nothing inherent in the story the glass could tell, but the value

38 Douzinas Costas and Ronnie Warrington with Shaun McVeigh Postmodem Jurisprudence: The Law of Text in the Text of Law Routledge London 1991 p 160. 
and meaning come from the discursive and narrative elements related to the glass. The legal enterprise cannot bridge the aporia between the res and verba, and the object will remain meaningless and empty along with its physical deficiencies. So the object itself then becomes a site of instability because of the reliance on the res, and by allowing the disconnection between the object and the narratives and discourses surrounding it, the legal enterprise can be complicit in denying the existence of a cultural significance, even if this is not its intention. How the law tries to overcome this problem will be considered in the final part of this article, in considering the fate of 'a piece of moulded gunmetal decorated with a ribbon'.

\subsection{The Protection of Movable CuLtural Heritage ACT. The Cultural Significance Provisions}

As already noted, the PMCH Act provides a set of benchmarks to determine whether a particular object is so fundamentally valuable to Australia that it should never be exported. The legislation is extraordinary in a number of respects, not least because of its complexity, being made up of a range of interlocking provisions based in and around a core set of provisions within the body of the legislation, and then supplemented by a generalised list of objects that are potentially capable of meeting the ultimate test of their significance to Australia. ${ }^{39}$ The most precise set of information about the objects to be protected under the legislation are contained in the National Cultural Heritage Control List ('the List') contained in the regulations accompanying the PMCH Act, which were intended to form the 'movable cultural heritage of Australia', and are objects that are of 'importance to Australia' for ethnological, archaeological, historical, literary, artistic, scientific or technological reasons. ${ }^{40}$ Why some objects are to be given the protection of the

39 The List is divided into the two classes: Class A and Class B. Class A objects can never be permanently exported, but can be given a certificate of exemption for export in limited circumstances, while Class B objects can only be exported if a permit or certificate is granted: Protection of Movable Cultural Heritage Act 1986 (Cth) s 8 (2) (a) and s 8 (2) (b).

40 Protection of Movable Cultural Heritage Act1986 (Cth) s 7 (1) enumerates a list of specific objects, though these may be expanded upon within the Regulations:

(a) objects recovered from:

(i) the soil or inland waters of Australia;

(ii) the coastal sea of Australia or the waters above the continental shelf of Australia; or

(iii) the seabed or subsoil beneath the sea or waters referred to in subparagtaph (ii); ${ }^{40}$

(b) objects relating to members of the Aboriginal race of Australia and descendants of the indigenous inhabitants of the Torres Strait Islands;

(c) objects of ethnographic art or ethnography;

(d) military objects;

(e) objects of decorative art;

(f) objects of fine art;

(g) objects of scientific or technological interest;

(h) books, records, documents or photographs, graphic, film or television material or sound recordings;

(j) any other prescribed categories (there is no (i) 
legislation is capable of operating within a highly contested terrain, ${ }^{41}$ but what may seem extraordinary to a casual observer is that objects are not named or defined with precision.

The cultural significance provisions, along with administrative materials such as forms and guidelines, are used to 'construct' an object's cultural significance. This needs some explanation. While a vast range of objects may be considered culturally significant, the cultural significance provisions rarely name, describe or otherwise identify any one specified object. Instead, a general taxonomic approach is used to identify in general terms whether an object is potentially protectable, which means the object is then subjected to a 'cultural significance' assessment using the practices of the museums sector to find out if the object should be kept within Australia.

Only two objects are named and described with precision: ${ }^{42}$ Ned Kelly's armour worn at the siege of Glenrowan, ${ }^{43}$ and since 1997, named recipients of the Victoria Cross medal. ${ }^{44}$ The facts of the object, as such, are predetermined, and are capable of meeting the expectation of the 'fact' of the object, within the practices and methods of law's empiricism of the object. The rest of the objects potentially affected by the legislation confound these expectations, and do not make sense within the fact/opinion divide that law assumes about objects. As will be seen shortly, the objects only make sense as discursive objects, but one factor should become apparent at this point - the existence of an object is presupposed by this legislative regime. The physical or inherent value of the object may become relevant to include or exclude an object from a series of refining factors contained in the National Cultural Heritage Control List, but its physical existence is not presupposed by an inherent value.

\subsection{Working Through the List}

But for the vast bulk of objects, there is no naming or description of a pre-defined object like Ned Kelly's armour, only a set of taxonomic determinates contained in the List. ${ }^{45}$ They subtly explain what delineates culturally significant objects from commonplace or everyday objects, and include a series of defining and refining provisions, which are discursive and ascriptive tools to determine an object's cultural significance. Within their broad categories, such as Objects of Applied Science or Technology in Part 4 or Objects of Fine or Decorative Art in Part 5 of the

41 Leiboff Marett 'The Embodiment of Culture: the Protection of Movable Cultural Heritage Act 1986 (Cth)' (1999) 12 Australian Feminist Law Joumal 3.

42 Both are Class A objects (which can never be exported)

43 National Cultural Heritage Control List, Part 9, 9.2A.

4 National Cultural Heritage Control List, Part 7, 7.3.

45 The current categories of object in the List are:

Part 1:Objects of Australian Aboriginal and Torres Strait Islander Heritage

Part 2:Archaeological Objects

Part 3:Natural Science Objects

Part 4:Objects of Applied Science or Technology

Part 5:Objects of Fine or Decorative Art

Part 6:Objects of Documentary Heritage

Part 7:Numismatic Objects

Part 8:Philatelic Objects

Part 9:Objects of Historical Significance 
List, hundreds of objects of different types and characteristics are listed. Again they are not named, but are types, including locomotives, ${ }^{46}$ musical instruments, ${ }^{47}$ or badges, tokens or charms, ${ }^{48}$ motor vehicles, objects relating to missionary activity, ${ }^{49}$ and objects relating to the development of Aboriginal or Torres Strait Islander protest and self-help movements. ${ }^{50}$

To find whether a specific object may be caught by the legislation, the broad scope of the List will have to be consulted, by examining the details found in each category, sub-category, and object type. For these objects, nearly all of them Class B objects (most of which will be allowed to leave Australia in any case), some kind of undefined, initial, ascriptive process has to be used to work out if the object at hand is included in the List at all. As such, the discursive basis for the object's cultural significance is interrogated and interpreted. The process of ascription involves the construction of the discursive account of an object's cultural significance, and is used in contradistinction to the 'description' of an object, the latter being based on the ability to use the senses to make observation about objects based on the form, materials, and physical characteristics of the object. In part, this meaning applies some of the exclusionary criteria in the List and the Regulations, designed to limit the number of objects potentially caught within its scope. These criteria are fundamental to the process of ascription.

\subsection{Making a Decision}

What is problematic within the kind of analysis that the legal enterprise usually relies on is to delineate the 'reasons' that make an object valuable into the language of opinion. Yet this is not what the legislative schema of the cultural significance provisions indicate. Instead, the taxonomic and general listings contained in the schema require a cultural significance ascription to fill in the gaps left open between 'unfilled' object and the discursive factors that makes the object culturally significant. A conceptual gap has to be filled, caused by this elision, which will connect the discursive features of the object into its actual form, and vice versa. The filling of this elision - from general listing to specific object and vice versa - occurs through the agency of the human actors who are involved in constructing the discourses surrounding the object. This process begins with the details contained in the application form completed by applicants, moves through the assessment form completed by the expert examiners, and continues in the hands of the Minister and the AAT. At each stage, the gaps left by the cultural significance provisions are filled out by the various actors involved in the process.

The object's status is constructed through this process, because no actual object is as 'general' as the description of its type in the List. The process of ascription both tells us what the object is, and establishes the story that connects it to its 'type', which partly reflects the reasons for an object's importance in s 7 (1). But the cultural significance provisions have left spaces open, where an unformed object has to be given some connection back to the general contents of the list.

\footnotetext{
46 National Cultural Heritage Control List, Part 4, 4.4 (d) (i).

47 National Cultural Heritage Control List, Part 5, 5.3 (4).

48 National Cultural Heritage Control List, Part 7, 7.4 (a).

49 National Cultural Heritage Control List, Part 2, 2.3 (f).

50 National Cultural Heritage Control List, Part 1, 1.4 (c).
} 
It needs to be emphasised that this process does not simply establish what the object is as a question of fact, opinion, or attribution. Instead, this process creates a series of legal tests to determine the status of the object relative to other objects of the same type, and to Australia's cultural heritage in general. ${ }^{51}$ This preliminary step is largely unaccounted for in the legislative schema and it has been overlooked in commentary of the cultural significance provisions. ${ }^{52}$ Through this preliminary step, the object's cultural significance is 'constructed', using methods akin to the narrative and discursive techniques of the new museology. Once it is decided that the object is a Class B object, it then has to be assessed again, against the key provision of the legislation s $10(6)$, which requires that the decision maker

(a) shall have regard, among other things, to the reasons referred to in subsection 7(1) that are relevant to the object to which the application relates; and

(b) if satisfied that the object is of such importance to Australia, or a part of Australia, for those reasons, that its loss to Australia would significantly diminish the cultural beritage of Australia-shall not recommend the grant of a permit, or grant a permit, as the case may be, to export the object permanently. (Emphasis added)

Central to this process is $\mathrm{s} 10$ (6) (b), which is used to decide whether the object is to be refused an export permit, because of its high degree of cultural significance. Decision-making, whilst in the hand of the administering Minister, is guided by an expert body - the National Cultural Heritage Committee ('the committee') - who considers assessments about objects by expert examiners. Section 10 (6) does not, as it were, stand alone, though it is the final and substantial test used to decide whether, ultimately, a culturally significant object is so significant that it must remain in Australia.

\subsection{A Piece of Moulded Gunmetal Decorated With a Ribbon}

As the account of the cultural significance provisions shows, they are not concerned with the fact of the object as such; rather it is what makes the object so special that it must remain in Australia. But in Re Truswell, ${ }^{53}$ which considered whether a Victoria Cross medal awarded to an Australian during World War One (then a Class B object) was culturally significant enough to be refused an export permit under s 10 (6), the AAT was unable to find a way to protect a physically insignificant object within the text of the cultural significance provisions. Indeed, it recognised that the value of each Victoria Cross 'entirely transcends its physical manifestation', ${ }^{44}$ but "on the

51 Re Truswell and Minister for Communications and the Arts (1996) 42 ALD 275, 294 [120].

52 See generally, Tolhurst Gregory J 'An Outline of Movable Cultural Heritage Protection in Australia' (1997) 2 Ant Antiquity and Law 137; Adamovich Barbara 'The Protection of Movable Cultural Heritage and the Waverley System: A Study of the Australian and United Kingdom Export Controls Relating to Cultural Property' (1998) 3 Media and Arts Law Review 4.

53 Re Truswell and Minister for Communications and the Arts (1996) 42 ALD 275.

54 Re Truswell and Minister for Communications and the _4rts (1996) 42 ALD 275, 295 [125]. 
basis only of its physical characteristics ... there would be no question of withholding an export permit'. 55

The fact of the object was meaningless - a piece of old gunmetal and a ribbon. So having reconstructed the legislative schema to impose the methods of the empiricism of the object despite the discursive structure contained within the, the AAT decided to overcome the interpretative dilemma it created by introducing the fact/opinion division in the decision-making provisions of the PMCH Act. For fact, read tangible, for opinion, read 'intangible', which the AAT 'found' within the phrase the 'cultural heritage of Australia' in s10 (6) (b). ${ }^{56}$ Through the existence of this intangible, the Victoria Cross was found to be culturally significant enough to be protected and therefore it was refused an export permit. Victoria Cross medals awarded to named Australians are now protected as Class A objects. ${ }^{57}$

Yet there was no need at all to introduce the tangible/intangible or fact/opinion division into the structure at all, and if the AAT had better understood the discursive nature of the assessment provisions of the PMCH Act, it would have realised that there the physically insignificant nature of the object had nothing to do with its cultural significance. Indeed, by relying on law's empiricism, the AAT incorrectly interpreted the cultural significance provisions because it had to negate the problem of the physically insignificant 'piece of moulded gunmetal decorated with a ribbon'. ${ }^{58}$ Assuming that objects exist by the fact of their verifiable physicality - the stuff of law's empiricism - it re-read the object to its detriment. It adopted the same approach as the person who described a Spitfire as 'aluminium junk', who also sucked the cultural significance from the Spitfire by focussing on the physical. It will be argued that if the AAT had conceived of these objects as constructed by their discursive and ascriptive framework, the text and meaning of the cultural significance provisions themselves held the key to deciding that the Victoria Cross was culturally significant enough to be refused an export permit. If it had adopted this method, the AAT would not have had to create an intangible to protect the Victoria Cross.

Re Truswell provides an extraordinary case study because the AAT's reasoning betrays the extent to which law's empiricism of the object is so ingrained within the legal imaginary that even when a legal framework expressly conceives of objects in a more discursive sense, law reimposes its logic onto the field. In part, I will suggest, the AAT misconceived the nature of the object because it relied on the interpretation of the cultural significance of an expert who was unfamiliar

55 Re Truswell and Minister for Communications and the Arts (1996) 42 ALD 275, 295 [125].

$56 \mathrm{Re}$ Truswell and Minister for Communications and the Arts (1996) 42 ALD 275, 294 [119] - [120].

57 National Cultural Heritage Control List Part 7, 7.3

While medals and other military objects have been included in the National Cultural Heritage Control List since it took effect in 1988, these objects had only been protected as Class B objects. Originally, only medals awarded before 1920 were listed, the year after Australia attended the post-war conferences as a nation in its own right, though Victoria Crosses awarded after 1920 were listed in 1993. Yet Australia's military victories and defeats were among the earliest kinds of heritage or culturally valuable objects recognised after Federation, hastened by the Gallipoli legends and the nationdefining consequences of Australia's involvement in World War One. But World War One Victoria Crosses were not Australian as such. However, the RSL, in particular, had attempted to prevent the sale of all Victoria Crosses, by trying to get them reclassified as Class A objects, and were ultimately successful. Except where families of awardees and living recipients want to take their medals from the country, they cannot be exported from Australia.

Re Truswell and Minister for Communications and the Arts (1996) 42 ALD 275, 295 [125]. 
THE AUSTRALIAN FEMINIST LAW JOURNAL 2007 VOLUME 27

with the techniques and methods of the discursive object, who instead relied on techniques familiar to law: an outmoded empiricist practice which assumed that the value of an object could be divined from its physical presence.

\subsection{A Difference of 'Opinion': Reviewing the Refusal to Export Major Towner's Medals}

In a sense, the value of the Victoria Cross medal is discursively straightforward, because they are so rarely awarded. They signify something very special and unique, though their connection with wars makes them a contested cultural space. ${ }^{59}$ Many recipients do not survive the circumstances which led to their award, but the recipient of these medals did. They had been awarded to Major Towner for his bravery on the battlefields of Flanders during World War One, but had been acquired by $\mathrm{Mr}$ Truswell, a dealer in medals who, in 1994, applied for a permit to export Major Towner's Victoria Cross and another medal, the Military Cross.

As required by the legislation, the application was considered by the National Cultural Heritage Committee after being sent to three expert examiners for assessment. Two out of the three of them recommended that the permit not be granted, and the Committee agreed with their assessment. It recommended that the Minister refuse to grant the export permit, which he did. Included in the reasons for refusal was that the decorations and medals were of substantial cultural significance to the nation and the Victoria Cross was a material reminder of the specific events surrounding its award. The Minister noted that the weight of professional advice given to him was that the cultural heritage of Australia would be significantly diminished by their export, ${ }^{60}$ but Mr Truswell sought a review the Minister's decision to the AAT because of the different assessment given the objects by the expert examiners.

The AAT characterised these as the different conclusions about the medals reached by the expert examiners, based on 'the facts' in the case. ${ }^{61}$ However, adopting a construction of the review based on the 'facts' does not sit well with the process of ascription provided for in the cultural significance provisions, and nor does it accord with the discursive framework of cultural significance ascription. I will suggest a slightly different construction may be more effective in establishing what the expert examiners had done. The review was based on differing interpretations about the relative cultural significance of these particular medals to Australia, and the tests and methods used by the expert examiners that led them to their conclusions. In other words, the AAT did not appreciate that the differences between the expert examiners were not based on their conclusions about the medals, but through the processes they used to reach those conclusions. Indeed, when the AAT set out its account about the Victoria Cross, the award of Major Towner's medals and the circumstances surrounding their award, they were also engaging in the processes

\footnotetext{
59 This is not to say that there is a uniform acceptance of the value of the Victoria Cross: George Couvalis and Cheryl Simpson, 'Anzac Heritage or Anzac History: Truth or Fiction?' (2000) 25 Altemative Law Joumal 165.; Cheryl Simpson, 'Object and Identity', Crossings (2001) 6 <http://asc.uq.edu.au/crossings/6_3/content/page_21>.

60 Re Truswell and Minister for Communications and the Arts (1996) 42 ALD 275, 278-279 [11].

61 Re Truswell and Minister for Communications and the Arts (1996) 42 ALD 275, 279 [12].
} 
of cultural significance ascription, not based on facts per se, but on the discursive factors that contributed to the story that made those medals culturally significant.

This is because one of the expert examiners refused to accept that there was a connection between the physical object and the discursive factors that were constructive of its cultural significance. As a result, when the AAT interpreted the meaning of the various aspects of the cultural significance provisions in this case, it was responding directly to his views that a physical object bears no relationship to the history surrounding the object, and this object was only important for symbolic and emotional reasons. It allowed the AAT to reimpose the logic of law's empiricism, to distinguish between the fact of the object and opinions about it.

\subsection{Negating the $\mathrm{VC}$ - the Fact of the Object}

Mr Anthony Staunton, was a Project Officer in the Department of Veterans' Affairs who had written extensively in the field of medals and decorations and their recipients. Among other things, he had been made an Honorary Fellow of the Australian War Memorial in 1994, ${ }^{62}$ and his knowledge of awards of military medals was clearly of a high level, but it was based around finding out information about the recipients of these awards. ${ }^{63}$ Indeed, he stated that: 'I've been writing articles all my life on the VC and I haven't had to have it in front of me to give recognition to that'. ${ }^{64} \mathrm{He}$ recommended the export permit be granted, because the export of Major Towner's medals would not result in a significant cultural loss to Australia. ${ }^{65}$ In his view:

Unlike a painting or a sculpture there is nothing intrinsically Australian in a Victoria Cross. It is merely a symbol of an [sic] happening, the reward given to a brave man who distinguished himself in the horrors of war. The momento [sic] itself is not important, what is important is the [sic] what it symbolises. ... it would be wrong to misuse this Act to pretend there was some cultural significance for preventing the Towner VC group leaving Australia when in fact the only argument for its retention is purely emotional. ${ }^{66}$ (emphasis added)

However, he conceded that each medal is unique, and recipients tend to be regarded with great respect in the community, ${ }^{67}$ though Towner's memory would live on whether or not his medals were exported. ${ }^{68}$

62 Re Truswell and Minister for Communications and the Arts (1996) 42 ALD 275, 283 [46].

63 Re Truswell and Minister for Communications and the Arts (1996) 42 ALD 275, 283 [46].

$64 \mathrm{Re}$ Truswell and Minister for Communications and the Arts (1996) 42 ALD 275, 284 [53].

65 Re Truswell and Minister for Communications and the Arts (1996) 42 ALD 275, 284 [47].

This phrase echoes the words used in PMCH 5: Expert Examiner's Assessment Form. Part B: Cultural Loss to Australia, which asked among other things 'In what way do you consider the export will or will not result in a significant loss to the cultural heritage of Australia?'. However, these words differ from the text of s 10 (6) (b) to which they appear to relate, thus altering their meaning.

$60 \mathrm{Re}$ Truswell and Minister for Communications and the Arts (1996) 42 ALD 275, 284 [47].

$67 \mathrm{Re}$ Truswell and Minister for Communications and the Arts (1996) 42 ALD 275, 284 [51].

$68 \mathrm{Re}$ Truswell and Minister for Communications and the Arts (1996) 42 ALD 275, 284 [50]. 


\subsection{The Discursive VC}

On the other hand, the other two expert examiners recommended that Major Towner's medals be retained in Australia. Both were curators at major collecting institutions in Australia, and unlike Mr Staunton, were familiar with discursive and narrative methods of ascribing and assessing the cultural significance of objects. Their observations accord with the view that it is not simply the medal as a pbysical entity, but the circumstances surrounding its award, that was highly relevant to its status for Australia, and its cultural significance. Unlike Mr Staunton, neither expert examiner considered the object in terms of its emotional or symbolic value, and instead concentrated on its historical significance — one of the reasons set out in $\mathrm{s} 7$ (1) on which an object's cultural significance is based for the purposes of s 10 (6) (a).

Major 'Bill' Billett was Senior Curator, Arms and Art at the Museum of Victoria, who had previously had a long-standing career in the Royal Marines and the Australian Army, and held an $\mathrm{MA}$ in history. ${ }^{69}$ Included in his reasons for recommending that the export permit be refused were the circumstances of the award of Major Towner's Victoria Cross, which was 'of outstanding significance because of the location and operation for which it was awarded', as the capture of Mont St Quentin was the AIF's most brilliant achievement of the First World War. ${ }^{70}$ More generally, Major Billett observed that:

The award of the VC was made personally to an Australian by the Sovereign for valour in an action by an Australian miliary formation in the service of the Empire. Within Australia, these awards are the tangible, visible, reminders of the nation's record of bravery in war. ${ }^{71}$

However, the Victoria Cross was also important in relation to Australia's developing nationhood. When called as a witness, he contradicted Mr Staunton's views about the relationship between an object and history:

Well, it's like a primary source document; it is - it is - the object is very important. The medals, the trophies brought back, the war relics all add to our stock of what we call our national history, and the very importance of the First World War was that there were certain breaks made with old traditions ... So all of these trophies from the First World War — and I would include the Victoria Crosses and the individual medals as well - they are all adding to our stock of what we call our history and our military heritage. So from that point of view, yes, they're extremely valuable. ${ }^{72}$

The other expert examiner, Mr Burness was the Senior Curator of Military Heraldry and Technology at the Australian War Memorial. He held a Degree of Applied Science in the field of

69 Re Truswell and Minister for Communications and the Arts (1996) 42 ALD 275, 285 [56].

70 Re Truswell and Minister for Communications and the Ants (1996) 42 ALD 275, 285 [57].

71 Re Truswell and Minister for Communications and the Arts (1996) 42 ALD 275, 285 [57].

72 Re Truswell and Minister for Communications and the Arts (1996) 42 ALD 275, 285 [59]. 
Cultural Heritage Management, and had 'been with' the Australian War Memorial for 22 years. ${ }^{73}$ He also recommended the medal not be exported, based on:

the remarkable respect and devotion which Australians have consistently shown to the VC and its recipients. It is the supreme award for gallantry and takes precedence over all other awards both civil and military. ${ }^{74}$

Indeed, while its physical form was central to its significance, it was the medal's relationship to the individual and community that mattered:

The cross itself is the material evidence of an act of supreme bravery performed in the most adverse circumstances. It is not only a recognition extended to an individual but it is evidence of the community's value of courage as a human ideal..$^{75}$

These two experts provided an analysis of the object that accorded with the assumptions about how objects were to be assessed under the cultural significance provisions, which was open to the concept that the object would be considered as a whole. But because of the methods $\mathrm{Mr}$ Staunton used, the AAT would fundamentally reconstruct the whole schema of the cultural significance provisions.

\subsection{The physical object}

Re Truswell was not the first case that considered the operation of the cultural significance provisions, but it was the first to re-read the structure of the legislation within the language of res and verba, fact and opinion, tangible and intangible. I will argue that because it sought to answer $\mathrm{Mr}$ Staunton's complaint that there were only emotional and symbolic reasons for protecting the object, the AAT could not find any scope within the legislative text to protect the object. It did so by fundamentally reconceiving the text and language of the legislative schema to find a way to explain why the Victoria Cross medal was culturally significant for Australia. As a matter of law, it distinguished the physical form of the medal from the discursive factors relating to the object's cultural significance. In doing so, it approved Mr Staunton's approach that the physical form of the object had to be distinguished from the narrative or intangible aspects of the object. Indeed, in relation to the meaning of 'movable cultural heritage' in s 7 (1), the AAT held that 'this description necessarily focuses upon the tangible and movable for it is dealing with objects of cultural heritage that are capable of export..$^{76}$ (emphasis added).

As a result, the AAT confined the 'movable cultural heritage' in $\mathrm{s}$ (1) as referring to a bare physical object. Its descriptors, whether they be ethnological objects, objects of fine art, objects of decorative art or any of the others listed in $s \quad$ (1) are empty. The AAT took its first step in restoring law's empiricism of the object in this gesture alone. The phrase - movable cultural

\footnotetext{
Re Truswell and Minister for Communications and the Arts (1996) 42 ALD 275, 286 [61].

Re Truswell and Minister for Communications and the Arts (1996) 42 ALD 275, 286 [62].

Re Truswell and Minister for Communications and the Arts (1996) 42 ALD 275, 286 [62].

Re Truswell and Minister for Communications and the Arts (1996) 42 ALD 275, 294 [119].
} 
heritage - was merely descriptive of a physical object, and therefore had no function in ascribing the cultural significance of objects, so the Victoria Cross medal:

comes within the description of movable cultural heritage and so is of importance to Australia, or a particular part of Australia, for ethnological, archaeological, historical, literary, artistic, scientific or technological reasons. That is to say, it is to be assumed that it is important to Australia for reasons given in sub-section $7(1) .{ }^{77}$ (emphasis added)

However, there is nothing in the text of $s$ (1) that makes any reference to the pre-supposition, or 'assumption', that the object is important to Australia. The AAT was led down this line of reasoning because it had interpreted these words as they related to a physical object only. If it had appreciated that the process occurs the other way around, meaning that the discursive factors are constitutive of the reason why an object is important to Australia, it would not have read the words of $s 7$ (1) down as it did. Indeed, s 7 (1) provides that:

A reference in section 8 to the movable cultural heritage of Australia is a reference to objects that are of importance to Australia, or to a particular part of Australia, for etbnological, archaeological, bistorical, literary, artistic, scientific or technological reasons, being objects falling within one or more of the following categories ... (Emphasis added)

But these reasons operate to subtly explain what differentiates culturally significant objects from commonplace or everyday objects, and the notion of 'importance to Australia' becomes a discursive and ascriptive tool to determine an object's cultural significance, supported by the Explanatory Memorandum, which shows that s 7 (1) was not to be read in such a limited way:

When considering the application, the expert examiner, the Committee and the Minister shall all take into account, amongst other things, the reasons listed in clause 7 which are relevant to the object the subject of the application and whether or not those reasons as elaborated in the categories and criteria prescribed in the Control List the object is of such importance that its loss would significantly diminish the cultural heritage of Australia. ${ }^{78}$ (emphasis added)

In other words, there was never an intention to divorce res and verba, fact and opinion in the range of factors that make an object significant, of which its physical form was one aspect only. Indeed, Clause 7 was entitled, and referred to the 'Movable cultural heritage of Australia'. ${ }^{79}$ This was reinforced in connection to the creation of the National Cultural Heritage Control List in clause 8:

77 Re Truswell and Minister for Communications and the Arts (1996) 42 ALD 275, 291 [104].

78 Protection of Movable Cultural Heritage Bill 1985 (Cth) Explanatory Memorandum, Clause 10: Grant of Permits.

79 Protection of Movable Cultural Heritage Bill 1985 (Cth) Explanatory Memorandum, Clause 7: Movable cultural heritage of Australia. 
The list will be based on the categories given in clause 7 and will set out for each category those criteria which will be used to determine whether or not an object falling within that category may be judged to be of such importance that its loss would significantly diminish the cultural heritage of Australia and should therefore become subject to export controls. 80

In this case, the AAT found that the Victoria Cross medal fell into $\mathrm{s} 7$ (1) for historical reasons. ${ }^{81}$ But the AAT merely identified the reasons, without linking the reasons to the object. However it noted that while:

it is to be assumed that the object is important to Australia for reasons given in $\mathrm{s} 7$ (1) ... it remains necessary to go behind this assumption to determine why the object is important. ${ }^{82}$

Even though it had already used a considerable amount of discursive material in considering the circumstances of the award of the Towner medals, the approach it adopted read down the 'teasons' in $\mathrm{s} 7$ (1) in such a way that meant that it operated simply as a condition precedent. This effectively stripped the discursive factors from the reasons why the object is important. In other words, the AAT has taken as a given that a Victoria Cross awarded in World War One is an object that is of importance for historical reasons, and not the other way around - that because of a series of circumstances and events that occurred at a particular time in the past, certain medals were awarded to specified individuals because of their actions, thus making the medals awarded a reference point to these events. It should be noted that the other two expert examiners adopted this approach towards the medals.

Curiously, it did not go on to consider why this Victoria Cross was important for historical reasons. ${ }^{83}$ Instead, it merely made reference to historical events, in deciding that there were intangible qualities of symbolism and emotion that meant the object was culturally significant for Australia. ${ }^{84}$ The closest it came to drawing a connection between the two was in its observation that

Certainly, it is the power of emotion which endows an otherwise unexceptional piece of gunmetal with the heroic status a VC possesses. But it is the power of emotion which is responsible for idealism, loyalty, patriotism, and so many other attributes to which we, as individuals and as a community, aspire. Similarly it is the

\footnotetext{
80 Protection of Movable Cultural Heritage Bill 1985 (Cth) Explanatory Memorandum, Clause 8: National Cultural Heritage Control List.

$81 R e$ Truswell and Minister for Communications and the Arts (1996) 42 ALD 275, 292 [107].

82 Re Truswell and Minister for Communications and the Arts (1996) 42 ALD 275, 291 [106].

83 Re Truswell and Minister for Communications and the Arts (1996) 42 ALD 275, 296-297 [131].

$84 \mathrm{R} e$ Truswell and Minister for Communications and the Arts (1996) 42 ALD 275, 295-296 [125].
} 
power of emotion, as well as reason, which makes us respect our history and learn from its lessons. ${ }^{85}$

While the other expert examiners were happy to connect the object to historical reasons, because the AAT had divorced the object from its discursive factors, it was no longer able to effectively rely on historical reasons to explain the Victoria Cross's cultural significance, and for this reason, it had to find a different explanation why the object should be protected.

\subsection{Undoing the Process of Ascription: Intangibles and the Cultural Heritage of Australia}

The AAT held that it had to consider the effect of the loss of the Victoria Cross upon Australia's cultural beritage (not its movable cultural beritage), in order to determine whether its loss would significantly diminish that cultural heritage. ${ }^{86}$ It held that it could not do this until it determined what was meant by the 'cultural heritage of Australia' ${ }^{87}$ In other words, it considered Australia's entire body of cultural beritage, not simply its movable cultural heritage to test the cultural significance of the Victoria Cross medal.

In order to find out what was meant by 'cultural heritage', it relied on cognate phrases and dictionary definitions, and that "While the term "cultural heritage" must be considered in the context of the Act, it is useful to consider the meanings which may be ascribed to these words' ${ }^{88}$ It did not refer to the definitions used in the 1970 Convention on The Means of Probibiting and Preventing the Illicit Import, Export and Transfer of Ownership of Cultural Property on which the legislation is based, the Second Reading Speech, or the Explanatory Memorandum, all of which would have given it a fuller and more complete understanding of the phrase in the context of this piece of legislation. Instead, relying on the dictionary meaning of the words 'cultural' and 'heritage', the AAT approved of a broad meaning of 'cultural heritage':

It follows from these dictionary definitions that the ordinary meaning of the words "cultural heritage" is a very wide one. Cultural heritage is that which is inherited by a society or group about its customs, achievements, products and outlook, its artistic and intellectual development and its forms, stages and types of intellectual development or civilization. It follows that cultural beritage includes not only tangible property such as objects or land but also the intangible such as customs, outlook, religion, folk-lore, music or bistory. ${ }^{89}$ (emphasis added)

\footnotetext{
Re Truswell and Minister for Communications and the Arts (1996) 42 ALD 275, 296 [129].

Re Truswell and Minister for Communications and the Arts (1996) 42 ALD 275, 294 [120].

Re Truswell and Minister for Communications and the Arts (1996) 42 ALD 275, 292 [108].

$R e$ Truswell and Minister for Communications and the Arts (1996) 42 ALD 275, 292 [109].

Re Truswell and Minister for Communications and the Arts (1996) 42 ALD 275, 292-293 [112].
} 
On the other hand, after looking at the Austratian Heritage Commission Act 1975 and the World Heritage Properties Conservation Act 1983, it took the view that while the former used the ordinary meaning of 'cultural heritage', 90 the latter used a meaning of 'cultural heritage':

which is narrower than the ordinary meaning ... (because it), adopts as its criteria in determining whether property is of outstanding universal value historical, artistic or scientific reasons and historical, aesthetic, ethnological or anthropological reasons. It does not focus upon other aspects of cultural heritage, such as customs, religion and folklore. ${ }^{91}$

But through the method it adopted, the AAT was able to construct a wide meaning for 'the cultural heritage of Australia', thus reinventing it as an 'intangible' designed to complement the lack of 'heritage' in a piece of metal. The 'cultural heritage of Australia' was to be broadly construed, so that the intangible would take up the slack of the lacking object:

That the description of movable cultural heritage focuses upon some aspects only of cultural heritage does not mean that a commensurately narrow meaning should be given to the words "cultural heritage" in sub-section 10(6). Sub-section 10(6) requires consideration of the effect of the loss of a particular object upon the cultural beritage of Australia. There are no words of limitation such as those in sub-section 7(1), and this accords with the essence of the scheme established by the Act, namely that the loss of the particular object is to be assessed against the whole of Australia's cultural heritage. For these reasons, we consider that the words "cultural heritage" should be given their ordinary meaning in sub-section 10(6). ${ }^{92}$ (emphasis added)

Relying on the tests it had developed in connection with the meaning of 'cultural heritage' as extending to customs, outlook, religion, folk-lore, music or history, the AAT was able to find a way to protect the Victoria Cross, and therefore directly respond to the Staunton's assertions that the only reason to protect the Victoria Cross was emotion and symbolism. The AAT held that a Victoria Cross':

value lies not in its tangible qualities but in its intangible. Its intangible qualities are twofold. The first is its symbolic quality. It symbolises courage, bravery, devotion to duty and self-sacrifice. It is public evidence of the very great value that we as a community place upon these qualities. A $V C^{\prime}$ s intangible quality also lies in its power to direct the community's attention to an event or time in its bistory. This is a quality shared by objects such as the Old Gum Tree at Glenelg in South Australia and the Dig Tree in New

90 Re Truswell and Minister for Communications and the Arts (1996) 42 ALD 275, 293 [115].

91 Re Truswell and Minister for Communications and the Arts (1996) 42 ALD 275, 294 [118].

92 Re Truswell and Minister for Communications and the Arts (1996) 42 ALD 275, 294 [120]. 
South Wales which is associated with Burke and Wills' last expedition. ${ }^{93}$ (emphasis added)

True enough, the AAT used the concept of the intangible to reinstantiate a form of discursive conception of the object in question. My point is that it didn't need to because the structure of the legislation provided the means by which the object would be interpreted. Instead, the AATs approach treated the physical object as separate from its narratives, rather than being one of the range of factors that created its value. Having established that intangibles can be included within the meaning of 'cultural heritage', the AAT was able to disregard the limitations of the physical object, 'the piece of gunmetal decorated with a ribbon':

There is thus nothing Australian about its origins or its physical properties. The ... medals regarded as Australian have acquired their Australian identity solely through the nationality of their recipients. But it could not be said that this in any way diminishes the Australian flavour of those medals. ${ }^{94}$

In deciding whether this particular Victoria Cross should be protected, the AAT then considered it against s $10(6)(b)$, and have regard to the individual qualities of the particular medals for which the permit is sought'. ${ }^{25}$ It refused to consider the Australian Victoria Crosses as a class because to do so would require the establishment of a 'priority of significance between them. To do so would be repugnant to the whole notion of VCs as unique symbolic objects. ${ }^{96}$ (emphasis added). Thus:

It does mean that we must consider these particular medals and ask ourselves whether they are of such importance to Australia for historical reasons that their loss would significance diminish this country's cultural heritage. ${ }^{97}$

It concluded that if the medals were to be exported, then they must be regarded as lost to Australia's cultural heritage. What would be lost would be an important or notable signpost to an outstanding Australian action in World War I and a symbol of heroic qualities which were exhibited in that action and which are themselves part of Australia's cultural heritage. As such, the loss of the medals would result in a significant diminution of Australia's cultural heritage. ${ }^{98}$ Therefore, the decision under review was affirmed. ${ }^{99}$

93 Re Truswell and Minister for Communications and the Arts (1996) 42 ALD 275, 295-296 [125].

94 Re Truswell and Minister for Communications and the Arts (1996) 42 ALD 275, 296 [127].

95 Re Truswell and Minister for Communications and the Atts (1996) 42 ALD 275, 296 [131].

96 Re Truswell and Minister for Communications and the Arts (1996) 42 ALD 275, 296-297 [131].

97 Re Truswell and Minister for Communications and the Arts (1996) 42 ALD 275, 296-297 [131].

98 Re Truswell and Minister for Communications and the Arts (1996) 42 ALD 275, 297-298 [136].

99 $\operatorname{Re}$ Truswell and Minister for Communications and the Ants (1996) 42 ALD 275, 298 [139]. 


\subsection{Emphasising the Physical}

As a result of its imposition of the empiricism of the object, the AAT incorrectly interpreted the cultural significance provisions by focussing on the verifiable characteristics — its insignificance, in effect - of the physical object, ${ }^{100}$ rather than the discursive factors that 'made' the object culturally significant. Clearly, the AAT did not disregard discursive factors relating to the Victoria Cross, because it had effectively based its reasoning on the discursive factors of emotion and symbolism. However, by reading down, and therefore disregarding, the role of $\mathrm{s} 7$ (1) and the National Cultural Heritage Control List in ascribing the object's cultural significance, it assumed that these discursive factors were dissociated from the object itself. By holding that $s 7$ (1) effectively only related to the physical aspect of an object, it narrowed the scope of the cultural significance provisions. As s 7 (1):

necessarily focuses upon the tangible and movable for it is dealing with objects of cultural heritage that are capable of export. That the description of movable cultural heritage focuses upon some aspects only of cultural heritage does not mean that a commensurately narrow meaning should be given to the words "cultural heritage" in s $10(6) \ldots$ There are no words of limitation such as those in $\mathrm{s}$ (1). ${ }^{101}$

There is no question that the legislation deals with physical objects, because the Act deals with physical things that can be moved. However, the AAT was wrong to interpolate the export function into $s 7$ (1). Indeed, the long title provides among other things that this is 'An Act to protect Australia's heritage of movable cultural objects', meaning that there is a presupposition that the objects are protected because they are culturally significant. However, the AAT reconstructed the meaning of 'movables' into conventional legal analysis, and as such treated the object as a meaningless chattel. By doing so, the AAT could treat the meaning of 'movable cultural heritage' as synonymous with a physical object, divorced from its narratives and ascription. For this reason, the only scope by which an object's cultural significance could be constructed was through s $10(6) .102$

It is argued that the AAT misconceived the intention of the legislature in interpreting 'movable cultural heritage' in s 7 (1) to refer merely to a bare physical object, even though it accepted that the reasons set out in $s 7$ (1) related to the object's importance to Australia. ${ }^{103}$ By reading $s 7$ (1) to mean the physical object, rather than the discursive factors on which the cultural significance of the object rested, it necessarily was unable to conceive of the object's cultural significance in relation to the meaning of the 'movable cultural heritage' in s 7 (1). It also disregarded the factors involved in ascertaining whether the object fell into the National Cultural Heritage Control List, which were constructive of its cultural significance. The 'movable cultural heritage of Australia' is thus more than a description of an object that has been identified for

$100 \mathrm{Re}$ Truswell and Minister for Communications and the Arts (1996) 42 ALD 275, 291 [106].

101 Re Truswell and Minister for Communications and the Arts (1996) 42 ALD 275, 294 [119] - [120].

102 Re Truswell and Minister for Communications and the Arts (1996) 42 ALD 275, 294 [120].

$103 \mathrm{R} e$ Truswell and Minister for Communications and the Arts (1996) 42 ALD 275, 291 [106]. 
consideration under s 10 (6). Otherwise, the detailed content of the list and its definers, qualifiers and delimiters, which give shape to the objects through the National Cultural Heritage Control List, are to be disregarded and rendered meaningless.

What is plain from the materials not referred to by the AAT is that the 'tangible' side of cultural heritage was not a distinct chattel or movable cultural heritage, or some kind of separate and super-added notion of the cultural heritage of Australia. The drafters of the legislation had understood the two notions were intimately connected, in conformity with current museological practice, which recognises the discursive and constructed nature of the object.

\subsection{Creating an Intangible - and an Emotion}

It is argued that the AAT's use of the phrase the 'cultural heritage of Australia' as the agent through which it could find an intangible to protect the Victoria Cross incorrectly interpreted the meaning and scope of the cultural significance provisions. Instead, s 7 (1) contained the tools through which the discursive factors on which the object's cultural significance could be based, and the earlier cases and the intention of the legislature support this approach. The AAT effectively disengaged the meaning of 'cultural heritage of Australia' in $\mathrm{s} 10$ (6) (b) from the physical form of the object. The 'intangibles' - customs, outlook and history - was the source of the object's cultural significance rather than the object itself. In effect, the Victoria Cross was rendered almost invisible.

The AAT had a source for the language of tangible/intangible. ${ }^{104}$ Prott and O'Keefe have argued that this language could provide a measure of protection for types of cultural heritage that were generally distegarded from cultural heritage protection: what they called intangibles of ritual, ceremony, or oral history, which could encompass notions of symbolism and emotion. Yet the concept of 'intangibles' betrays the dualism of fact and opinion, the sense that they fail to exist in a stable and determinable form that is not a component of the schema established by the PMCH Act.

Curiously, in interpreting the wide meaning of 'cultural heritage', the AAT was coy about the aspects of s $10(6)$ to which it referred when interpreting its meaning. However, it should be noted that the phrase 'cultural heritage' is only used in s 10 (6) (b). The AAT did not expressly limit itself to considering this sub-paragraph, and simply referred to 'section 10 (6)'. ${ }^{105}$ However, the AAT had already disregarded any possibility that s 10 (6) (a) was relevant to the meaning of 'cultural heritage', as this sub-paragraph referred back to $s 7$ (1), which had already been read down as only referring to physical objects. The legislative history also makes it clear that there would be flexibility between the cultural significance provisions, for $\mathrm{s} 7$ (1) and the List were to be constitutive of both cultural significance ascription and assessment. Nevertheless, through its use of the narrative of symbolism and emotion, the AAT relied upon the metaphysical trope, such as its truth, morality or its value as an aide memoire. 106 As the AAT observed:

$10+$ Prott Lyndel V and Patrick J O'Keefe"Cultural Heritage' or 'Cultural Property' (1992) 1 Intemational Joumal of Cultural Property 307

105 Re Truswell and Minister for Communications and the Arts (1996) 42 ALD 275, 294 [120].

106 Merryman John Henry 'The Public Interest in Cultural Property' (1989) 77 California Law Review 339 p 346-348. 
After all, it is the recipients, and their deeds of valour, which are generally acknowledged to be at the core of the VC's almost mystical value. ${ }^{107}$.... Certainly, it is the power of emotion which endows an otherwise unexceptional piece of gunmetal with the heroic status a VC possesses. ${ }^{108}$ (emphasis added)

It appears as if at least part of the reason why the AAT equivocated in its reasoning about the meaning of 'cultural heritage' in s 10 (6) was that it could not accommodate the emotions and symbols on which it based its decision within any of the 'reasons' why objects were culturally significant for Australia set out in s 7 (1). By founding the basis for the object's cultural significance in the affective domain — symbols and emotions - it was at best able to acknowledge the referent for the Victoria Cross's importance to Australia, namely for historical reasons. In this context, the AAT was prepared to make some far-reaching observations about the connection and significance of the circumstances surrounding the awarded medals for the Australian community. 109

\subsection{Different Methodologies}

In this case, by being drawn into a methodology and process alien to the legislative structure, the AAT constructed its interpretation of the cultural significance provisions to refute Mr Staunton's method of analysis which insisted on drawing a distinction between a physical object and its discursive framework. As a result, it disregarded the methodology of the curatorial experts in this case, who, it is argued, approached the construction of the cultural significance of the object in conformity with the expected practices of cultural significance decision-making - and the legislative schema. As a result, they had a language in which to explain why the object was important for historical, not emotional or symbolic reasons, and for this reason, it is argued that the AAT should not have disregarded the methodology used by the curatorial expert examiners.

Mr Staunton was an apparently dispassionate, impartial expert, with no known conflict about the medal. However, he was the only expert examiner who did not have curatorial experience, and he adopted a vastly different methodology on which to reach his conclusions about the cultural significance of Major Towner's' medals, which led him to a vastly different outcome. Mr Staunton had used an out-dated curatorial method to assess the object, where the object stands or falls only on its physical form. How the AAT tried to correct Mr Staunton's mistakes also betrays another fundamental misconception that these objects embody some kind of inherent value. ${ }^{110}$ Thus, a mere piece of gunmetal decorated with a ribbon is not enough on its own to be protected. 111

107 Re Truswell and Minister for Communications and the Arts (1996) 42 ALD 275, 296 [127].

108 Re Truswell and Minister for Communications and the Arts (1996) 42 ALD 275, 296 [129].

$109 \mathrm{Re}$ Truswell and Minister for Communications and the Arts (1996) 42 ALD 275, 279-280 [15] - [23].

110 eg Merryman (1989) above n 106; Merryman John Henry 'Counterfeit Art' (1992) 1 International Journal of Cultural Property 27.

11. Re Truswell and Minister for Communications and the Ants (1996) 42 ALD 275, 295 [125]. 


\subsection{Concluding, With A Post-Script}

As this analysis has shown, attempting to reach decisions about the cultural significance of objects using the physical object as the site of active decision-making is fundamentally flawed. But one of my claims may seem to have been rather far-fetched: that in some way, the reliance on the res leads to greater uncertainty about the status of the object than an understanding of the object as a whole, based in and around its narratives. This postscript to $R e$ Truswell suggests that this interpretation is in fact, as it were, thoroughly grounded in reality.

Two years after the decision in $R_{e}$ Truswell, the Towner medals made one final appearance as a Class B object under the PMCH Act, before Victoria Crosses were finally reclassified as Class A objects in 1998.112 On 5 February 1998, the Minister refused an application for an export permit for the Victoria Cross Medals group awarded to E T Towner MC. The Minister's reasons for refusing the export permit were the same, and again, two of the three expert examiners indicated that the cultural heritage of Australia would be significantly diminished by its export. It was also noted that the AAT had affirmed a decision of the previous Minister to refuse an export permit for the Towner Victoria Cross on a previous occasion. It was noted that no additional information or changed circumstances have arisen since the AAT's ruling in 1995.113 One other piece of information is rather important. That this new application was made after a new Minister (of a different political persuasion) took over responsibility for administering the legislation, is not a coincidence. The more closed the res, the more malleable the verba. In other words, if an object is read only as a physical thing, and the words or opinions on which its value exists is treated as a mere side-effect to the object, and not part and parcel of the value or significance of the object, it can be metaphorically re-read or reconstructed with impunity, and very, very irrationally. Law's empiricism of the object is, ultimately, an exercise in meaninglessness.

112 Above $n 57$.

113 Department of Communications and the Arts Annual Report on the operation of the Protection of Movable Cultural Heritage Act 1986 and the administration of the National Cultural Heritage Fund 1997-98 *5/18. <http://www.dcita.gov.au> at 26 October 1998. (Copy on file with author). 